\title{
Acute Physiology and Chronic Health
} Evaluation II Clinical Classification

National Cancer Institute

\section{Source}

National Cancer Institute. Acute Physiology and Chronic Health Evaluation II Clinical

Classification. NCI Thesaurus. Code 6121005.

A standardized rating scale developed by Knaus et al in 1985, which is a classification system used to measure severity of disease. This instrument uses a point score system based on physiological measurements, age and previous health status. 